\title{
Nephritis, Neuropsychiatric Lupus in Sickler Patient: A Case Report
}

Abdulsalam A Noorwali ${ }^{1}$ and Narges E Omran ${ }^{2^{*}}$

${ }^{1}$ Internal Medicine and Rheumatology, Umm Al Qura University Hospital, Saudi Arabia

${ }^{2}$ Internal Medicine and Rheumatology, Al-Noor Specialist Hospital, Saudi Arabia

*Corresponding Author: Omran NE, Consultant, Internal Medicine and Rheumatology, Al-Noor Specialist Hospital, Saudi Arabia, PO Box: 6251, Makkah, 21955, Saudi Arabia, Tel: +966 594421399; E-mail: nargesomran@hotmail.com

Rec date: September 22, 2017; Acc date: October 17, 2017; Pub date: October 23, 2017

Copyright: @ 2017 Noorwali AA. This is an open-access article distributed under the terms of the Creative Commons Attribution License, which permits unrestricted use, distribution, and reproduction in any medium, provided the original author and source are credited.

\begin{abstract}
The occurrence of systemic lupus erythematosus (SLE) in patients with sickle-cell disease (SCD) is rare. The relation between lupus disease severity and haemoglobinopathies like $b$ thalassemia is still unclear. We report Saudi women with sickle cell disease and active systemic lupus erythematosus who presented with lower limb weakness, and symptomatic anemia.
\end{abstract}

Keywords: Systemic lupus erythematosus; Lupus nephritis; Sickle cell disease; Haemoglobinopathies

\section{Introduction}

SLE is an autoimmune disease may affect many systems, the severity of involvement varied from patient to patient with remission and flare up periods, it is multi system disease. The diagnosis is usually based on clinical symptoms and signs as well as laboratory investigations including immunologic assessment, recently SLICC classification criteria used for the diagnosis of systemic lupus erythematosus [1]. Here we discuss a case of severe SLE associated with sickle cell disease diagnosed at the same time with involvement of central nervous system and kidneys which may cause by either lupus or sickle cell disease and need more investigations to specify the etiology, an association between SLE and sickle cell disease was reported in the literature, some cases occurred in children [2], and some other cases were reported with lupus nephritis in sickle cell patients $[3,4]$. The actual incidence of lupus in patients with sickle cell disease is unknown because The most cases in literature are case reports, the diagnosis of lupus in patients with known to have sickle cell disease is sometimes difficult and delayed due to similar presentations (arthralgia, anemia, central nervous system involvement, renal disease ...etc.) [5]. This is a case of Saudi woman (not known to have sickle cell disease) presented with neurologic symptoms and symptomatic anemia, after further evaluation proved to have SLE and SCD.

\section{Case presentation}

A 40 year old female Saudi patient, single, living in Makah, has strong family history of sickle cell disease, she presented to our hospital with history of gradual onset of distal and proximal limbs weakness, and numbness which was more on the lower limbs, arthralgia and bone pain, she became bedbound within one month, no sphincter involvement, no back pain, no history of trauma, no visual symptoms, she had chronic tension headache, loss of interest and was feeling down, but no suicidal attempt, no history of seizures, she had no history of mouth ulcers or photosensitivity, no chest or cardiac symptoms, no history of fever or weight loss, no previous hospital admissions or blood transfusion.
On clinical examination: she was conscious oriented with normal higher function tests, pale, afebrile, had alopecia and discoid lupus, no arthritis, no splenomegaly, Para paresis with power of 3/5 (lower motor neuron weakness), no sensory level, depression was assessed by beck depression scale [6] and showed moderate depression.

Blood investigations showed normocytic anemia: $6.9 \mathrm{~g} / \mathrm{dL}$, thrombocytopenia 58000, lyphocytopenia, positive coombs test, ESR $115 \mathrm{~mm} /$ first hours, CRP $3.2 \mathrm{mg} / \mathrm{L}$, normal liver and kidney function test, urine analysis showed active sediment, 24 hour urine.

Collection: Protein urea $5700 \mathrm{mg} /$ day, very low C3 and C4, positive (ANA, anti-ds DNA and anti-smith), anti cardiolipin and lupus anticoagulant: negative, vitamin B12 and foliate normal, hemoglobin electrophoresis test (Figure 1).

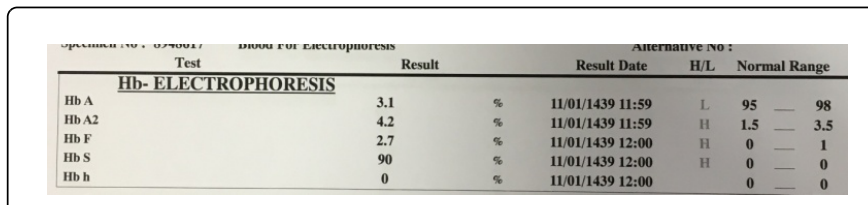

Figure 1: Hemoglobin electrophoresis test.

The results confirming a diagnosis of SCD a diagnosis of SLE was confirmed based on clinical and laboratory 2012 (SLICC) classification criteria for diagnosis of SLE [1], her disease associated with multisystem involvement (neuropsychiatric lupus, lupus nephritis, anemia, thrombocytopenia, discoid lupus), SLEDAI score was used to assess the disease activity [7] which showed severe active disease, nerve conduction study showed axonal polyneuropathy, MRI thigh showed myositis (Figure 2).

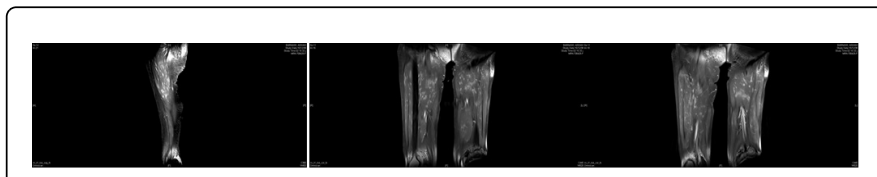

Figure 2: MRI thighs. 
MRI brain revealed mild brain atrophy and white matter and corpus callosum lesions suggestive of vascular disease. MRI for cervical ,dorsal and lumbar spine was normal, we started her on pulse Methylprednisolone 1 gram IV daily for 5 days and Mycophenolate mofetil $1500 \mathrm{mg}$ twice daily (as induction therapy for lupus nephritis) [8] and she was treated also with IVIG $[9,10]$ for total 5 days initially and she responded gradually, the power became grade $4+$ on follow-up and the patient was able to walk, aspirin, ACEI and hydroxychloroquine were added to treatment, renal biopsy was performed within one month and showed grade 4 lupus nephritis. She was started on antidepressant treatment as well (Figure 3) [11].

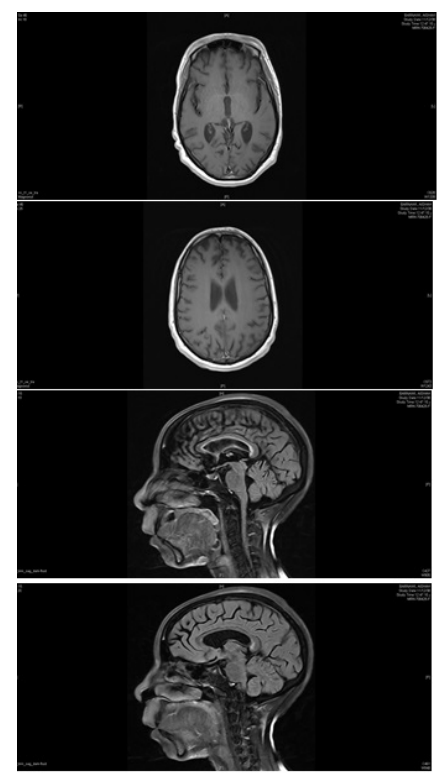

Figure 3: MRI brain.

\section{Discussion}

The association between SLE and SCD is uncommon, SLE and SCD are chronic diseases that have several clinical and laboratory findings in common [12], around 40 cases have been reported with SLE and SCD association, which is uncommon, most of them were African women, All cases were diagnosed as lupus at young age and known to have sickle cell disease many years before the diagnosis of lupus [5], we report the described case of Saudi woman with SLE and SCD overlap, in our case the symptoms started with peripheral nervous system involvement then diagnosed with sickle cell disease and severe active SLE wit multisystem involvement (neuropsychiatric lupus and lupus nephritis, thrombocytopenia, anemia, discoid lupus, myositis) our patient was almost asymptomatic for sickle cell disease and was not investigated or admitted to hospital due to sickle crisis or anemia and she did not receive blood transfusion before. Anemia is a common presentation for lupus patients occur with different types and severity, but rarely associated with haemoglobinopathies, hematologic manifestations of SLE are variable [13], lupus patient may have leucopenia, lymphopenia, thrombocytopenia, autoimmune hemolytic anemia (AIHA), which are included in classification criteria of SLE, Thrombotic Thrombocytopenic Purpura (TTP), and myelofibrosis which are not included in SLE classification criteria [14]. Few SLE patients were reported in literature with severe lupus associated with $\beta$ thalassemia which is rare association. Idiopathic nephrotic syndrome, focal and segmental glomerulosclerosis, membranoproliferative glomerulonephritis are known as renal complication of sickle cell anemia, our patient has lupus nephritis class 4 proved by renal biopsy, Articular involvement is the most common symptom in SLE/SCD patients the percentage is about $84 \%$ of cases in literature, less commonly sororities (36\%), then glomerulonephritis class III or IV occurred in $11 \%$ of SLE /SCD reported cases. In our reported case the articular manifestation was minimal and had no serositis, Cutaneous and neurologic manifestations in patients with SLE and SCD are rare in literature except for some cases with seizures and less commonly polyneuropathy [5] but our patient has discoid lupus, and also presented with severe polyneuropathy and myositis as well and has CNS vascular disease could be due to either lupus or sickle cell disease and has brain atrophy also which most likely due to sickle disease.

\section{Conclusion}

In this case who presented with severe active systemic lupus erythematosus with multisystem involvement (neurologic, hematologic, renal skin and muscle) an association with sickle cell disease was found, which is rare association and may affect the severity of systemic involvement especially renal and CNS systems, and may cause difficulties in diagnosis, we need to search more about the relation between lupus, other autoimmune diseases and haemogloginopatheis and its association with disease severity. Physicians should consider SLE diagnosis in SCD patients and may ask for hemoglobin electrophoresis in SLE cases if clinically indicated for the possible association between sickle-cell disease and systemic lupus erythematosus.

\section{Acknowledgments}

We would like to acknowledge medical team led by Dr. Mohammed Hasan and hematology team led by Dr. Ibrahim Sami, and special thanks for histopathology department.

\section{References}

1. Petri M, Orbai AM, Alarcón GS, Gordon C, Merrill JT, et al. (2012) Derivation and validation of the systemic lupus international collaborating clinics classification criteria for systemic lupus erythematosus. Arthritis Rheum 64: 2677-2686.

2. Saxena VR, Mina R, Moallem HJ, Rao SP, Miller ST (2003) Systemic lupus erythematosus in children with sickle cell disease. J Pediatr Hematol Oncol 25: 668-671.

3. Idris AB, Abdulgayoom A, Mudawi E, El Hassan AM, Elamin EM, et al. ( 2015) Coexistence of sickle cell nephropathy and lupus nephritis in a Sudanese child. Saudi J Kidney Dis Transpl 26: 584-588.

4. Minocha V, Rana F (2013) Lupus nephritis in a patient with sickle cell disease. Case Rep Hematol. 2013:907950.

5. Maamar M, Tazi-Mezalek Z, Harmouche H, Mounfaloti W, Adnaoui M, et al (2012) Systemic lupus erythematosus associated with sickle-cell disease: A case report and literature review. J Med Case Rep 6: 366.

6. Smarr KL, Keefer AL (2011) Measures of depression and depressive symptoms: Beck Depression Inventory-II (BDI-II), Center for epidemiologic studies depression scale (CES-D), geriatric depression scale (GDS), hospital anxiety and depression scale (HADS), and patient health questionnaire-9 (PHQ-9). Arthritis Care Res (Hoboken) 11: S454-466.

7. Gladman DD, Ibañez D, Urowitz MB (2002) Systemic lupus erythematosus disease activity index 2000. J Rheumatol 29: 288-291. 
Citation: Noorwali AA, Omran NE (2017) Nephritis, Neuropsychiatric Lupus in Sickler Patient: A Case Report. Gen Med (Los Angeles) 5: 302.

Page 3 of 3

8. Anders HJ, Appel GB (2012) Lupus nephritis: Implications of the new ACR lupus nephritis guidelines. Nat Rev Nephrol 8: 500-501.

9. Papo T (1999) Polyvalent intravenous immunoglobulins in systemic lupus. Rev Med Interne 4: 414s-418s

10. Lesprit P, Mouloud F, Bierling P, Schaeffer A, Cesaro P, et al. (1996) Prolonged remission of SLE-associated polyradiculoneuropathy after a single course of intravenous immunoglobulin. Scand J Rheumatol 25: 177-179.

11. Alsowaida N, Alrasheed M, Mayet A, Alsuwaida A, Omair MA (2017) Medication adherence, depression and disease activity among patients with systemic lupus erythematosus. Lupus 1: 961203317725585.
12. Robazzi TC, Alves C, Abreu L, Lemos G (2015) Coexisting systemic lupus erythematosus and sickle cell disease: Case report and literature review. Rev Bras Reumatol 55: 68-74.

13. Castellino G, Govoni M, Padovan M, Rizzo N, Trotta F (2005) $\beta$ Thalassaemic trait and systemic lupus erythematosus. Ann Rheum Dis 64: 653-654.

14. Fayyaz A, Igoe A, Kurien BT, Danda D, James JA, et al. (2015) Haematological manifestations of lupus. Lupus Sci Med 2: e000078. 